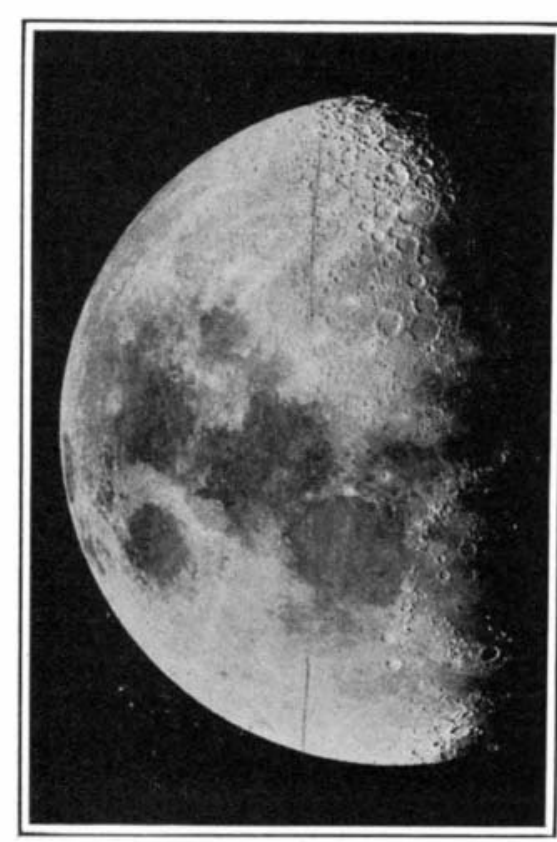

The moon, $8 \frac{1}{2}$ days old, as seen through the telescope.

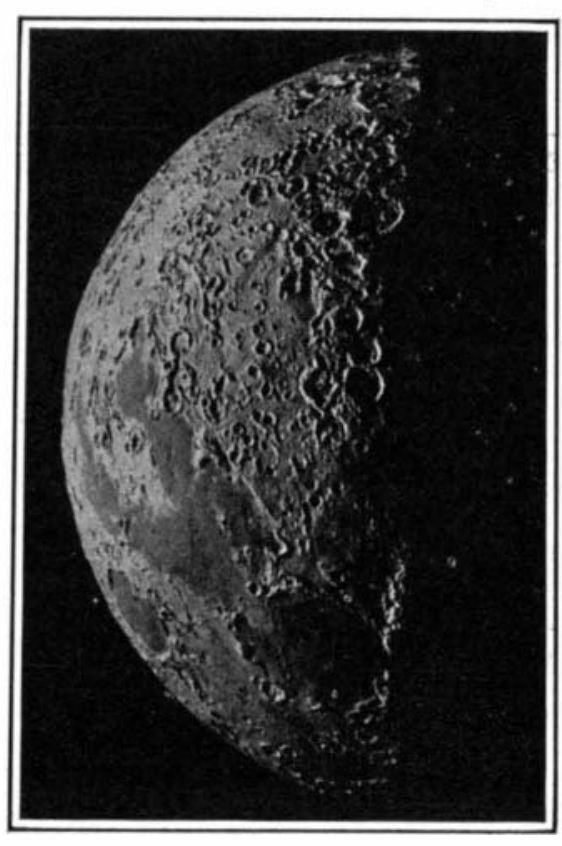

First quarter, as seen on the sculptured moon.

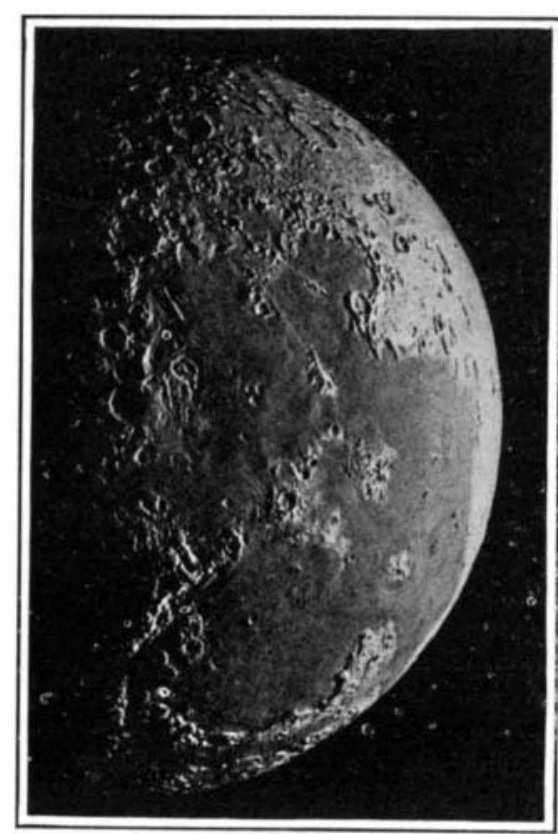

Last quarter, as seen on the sculptured model.

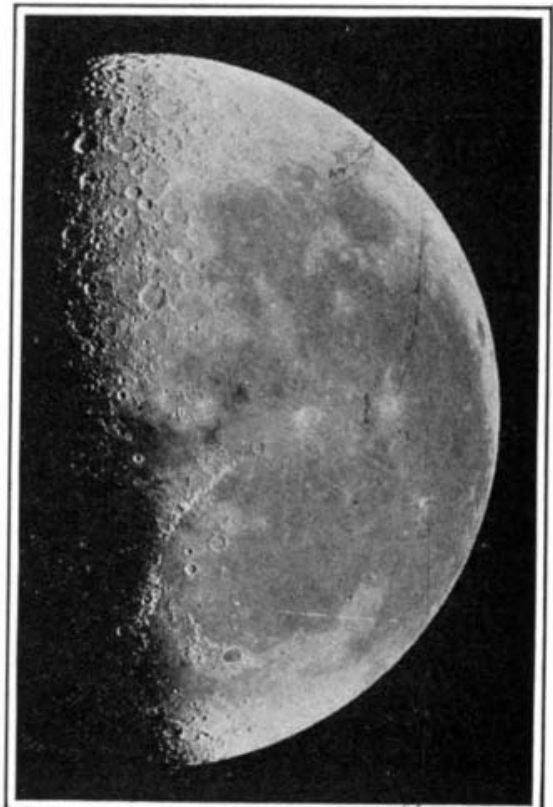

The moon, $201 / 2$ days old, as seen through the telescope.

\title{
How a Plastic Model of the Moon Was Made
}

The Hemisphere of the Moon Constructed After Telescopic Photographs

By Herbert Collier

AFTER some years of telescopic observation with a Brashear telescope I determined to undertake the task of sculpturing the moon, mainly for the purpose of at taining greater familiarity personally with every detail of the surface.

When you consider that the artist's model was some 240,000 miles away and had gained a reputation through the ages of being "fickle," some of the difficulties become apparent. Every day the moon has a different appearance-a new dress every sitting. As the sunlight creeps over the hills and lights up the mountain peaks, the view of yesterday changes, and quite a new aspect results. New valleys, great yawning crater jump into view with their dark depths untouched by even a glimmer of twilight, forming a background of Rembrandt's choosing. Continually the terminator, the irregular dawn line dividing light and darkness, is moving forward. On the earth this travels at the rate of about 1,000 miles an hour, completing the circuit of the globe in one day On the moon this movement is about 225 miles per diy, or nearly 10 miles an bour, for the earth turns round $291 / 2$ times to one revolution of the moon.

The details of craters-breadth and depth, a crag here, a precipice there---show clearly, contrasted by the shadows. But as the sun rises all this passes into blurry confusion in the fierce light of overhead rays. In such a moving picture there is a peculiar fascination. A new panorama presents itself each night to the watch ful eye. To see it all is impossible, as the moon is in the visible sky for but a few hours comparatively, and nightly vigils with the telescope are sure to be interrupted frequently by cloudy weather or bad atmospheric conditions. Thus a long course of looking is obligatory before the student by personal observation knows the surface of the moon thoroughly.

Though my eye had registered through the telescope thousands of impressions of the surface markings of the moon, I dare not trust that organ solely in transferring them to sculpture. Accuracy of result demanded exact measurements. Telescopic photographs present an unchanging record. They give an indelible impression of what is revealed, and such permanent record is ready for investigation at all times. Beyond question, photography pre-eminently has enabled astronomy to merit the title given it to-day "the most exact of sciences." Therefore I made, as the foundation of my work, the best series of photographs of the moon that the world has to-day, which is known as the Paris Atlas.

Twenty years ago M. Loewy, the gifted director of indertook the systematic photographing of the moon. A unique telescope was designed, and elaborate plans and specifications made for this remarkable undertaking. The instrument was an ingenious combination of a huge object-glass or light collector nearly two feet in diamter and mirrors Equatorially mounted and iniven by ojject across the sky, while the mirrors, two in number, were so arranged as to convey the image thus secured through a tube in the wall to the eye-piece situated within a comfortable room. Here the camera was attached, and the men worked free from the usual bodily discomforts associated with the ordinary telescope.

While some of the finest individual photegraphs of the moon have been taken by the great telescope at the Yerkes Observatory, which is the largest refracting telescope in the world, nothing can compare with the series secure by the Paris astronomers through years of devoted effort Thousands of photographs were taken of mew to full, and then on to new again. Possibly twenty would be secured one night and but one selected as good enough to enter the atlas. These pictures form a wonderful catalogue of the topography of the moon, presenting far

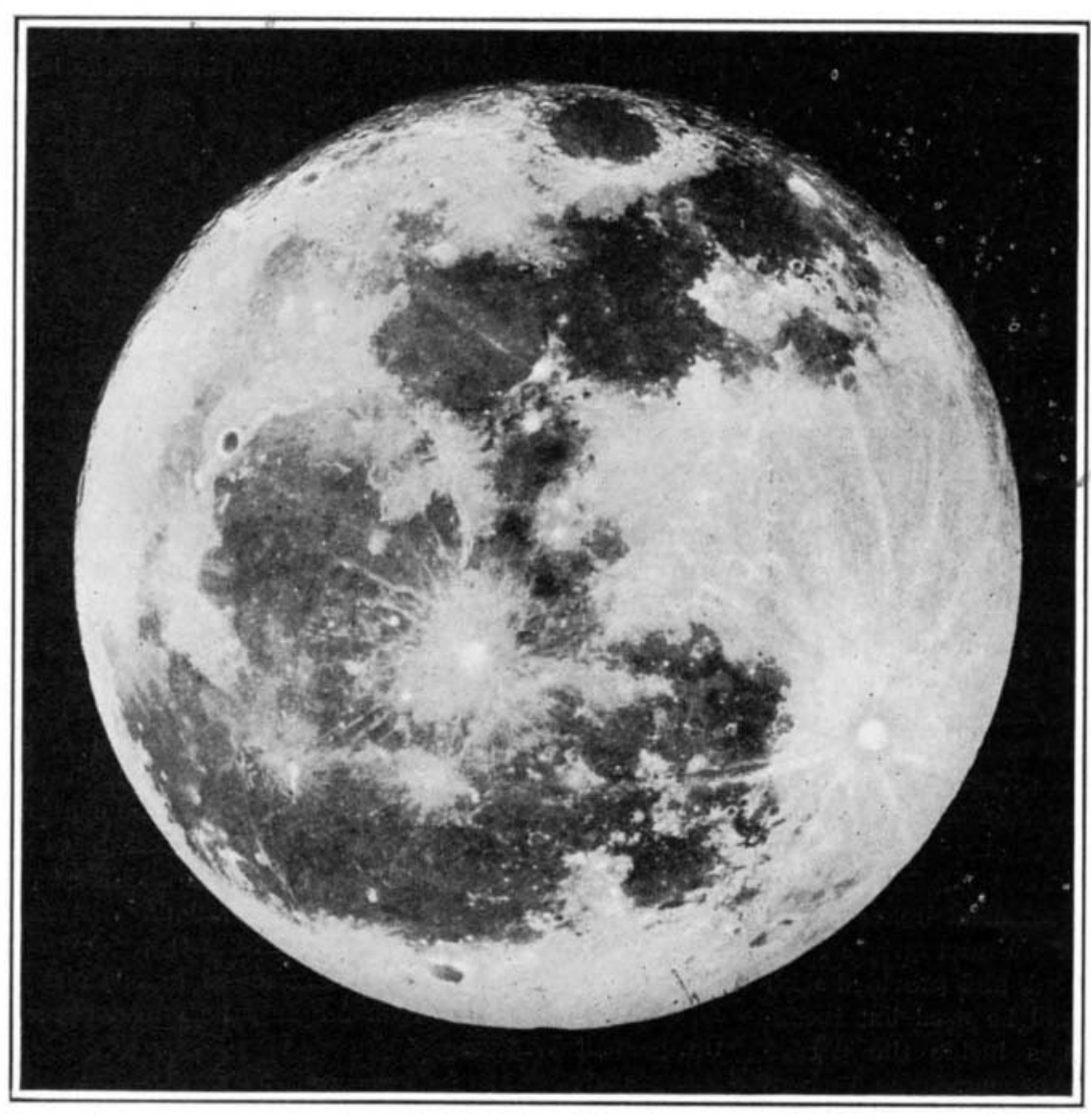

Full moon as seen in the telescopes.

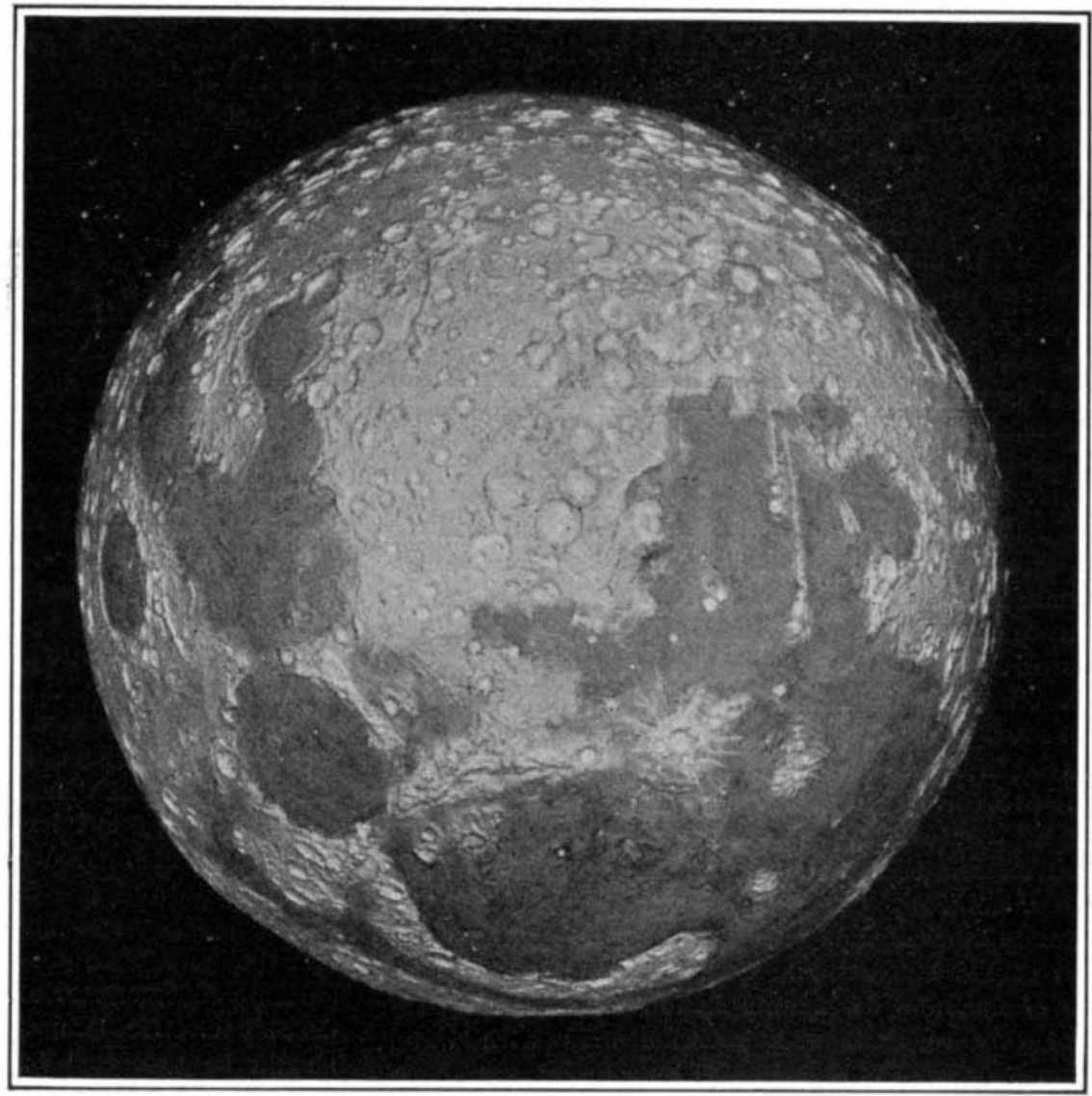

Full moon as it appears on the model. 


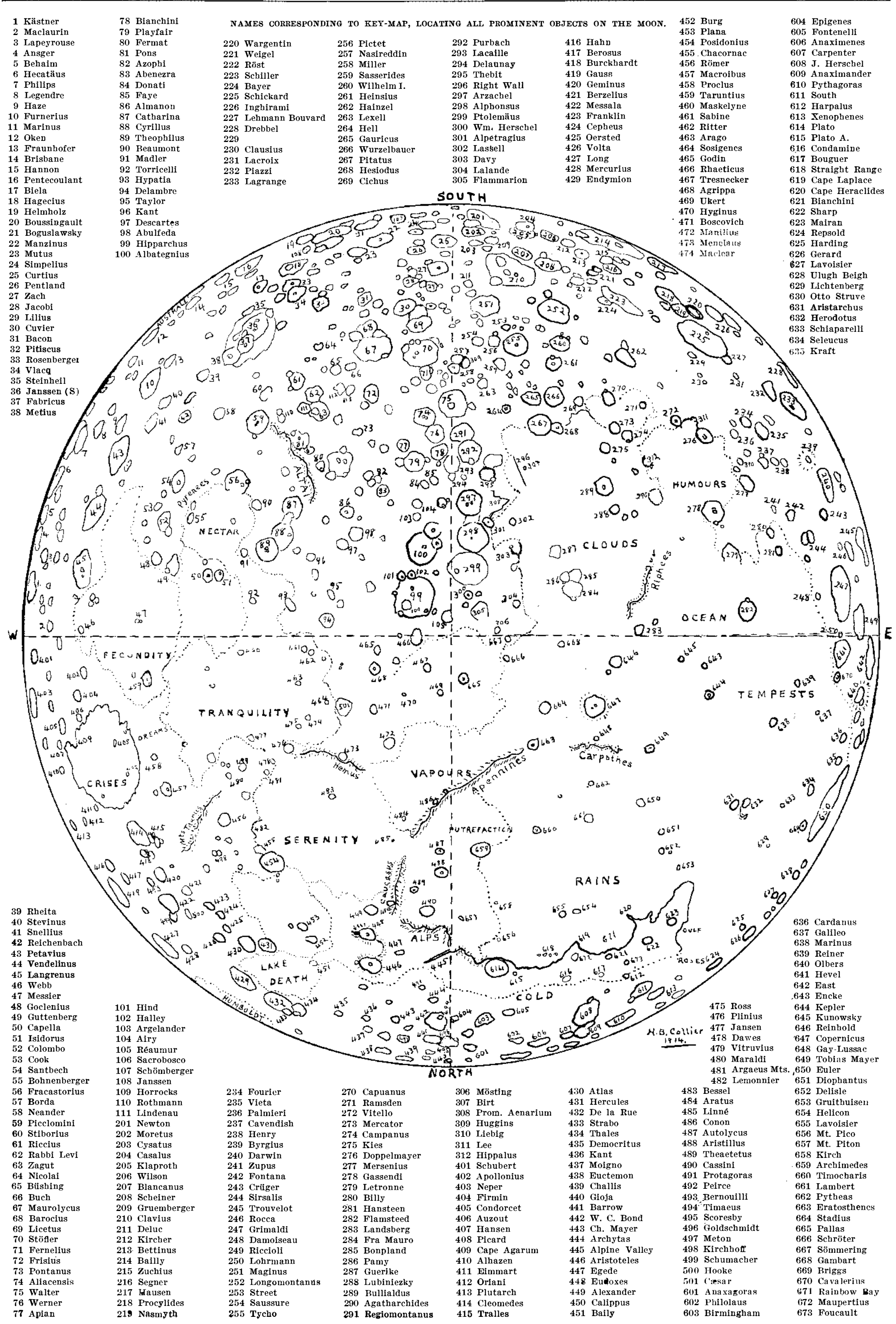


than we know of our earth in many regions. The atlas was to me a guide book superior to a personal visit.

Fearful lest through lack of knowledge of the technique of sculpture I should waste much valuable time, I devoted fully six months to the study of this special feature. Then after consultation with a number of skillful artists I commenced operations.

Plasticine appeared best suited to the conditions under which I was to labor. It is non-drying and responds quickly to manipulation with a tool. A sitting of three or four hours, then a day or two, and another sitting just as my spare time permitted, proved plasticine an excellent medium for the purpose.

"How big shall I make it?" was a troublesome question which received answer in the selection of a scale of 180 miles to the inch. The moon having a diameter of 2,160 miles, thus brought my work to a like measurement of 12 inches. This was a convenient workable basis and proved satisfactory in every respect.

Only half the moon is visible to us at any time, and, strange to say, it is always the same half. A presentation to "royalty" demands that madam turns not her back to the regal chair. The approach, the bow, and the retreat call for skillful manipulation of her troublesome train, but she must keep her face ever to the front So the moon sedately circles about the earth, and in true subservience observes this custom with remarkable precision. Every $291 / 2$ days the moon makes the circuit of the earth. At the same time she turn completely round. Yet with provoking constancy does she keep that one side to us. A slight swaying of the ball called "libration" permits a peep at times of a little more of the "edges" than the exact half, which really makes a total of about 59 per cent of the wole surface presented at different times to the earth. Consequently, half a sphere is really all we need to repre sent the details of surface characteristics of the earth's a foundation for my model I constructed a hemisphere of selected well-dried wood, laminated to prevent warping. The entire surface was then liberally treated with ing. The entire surface was then liberally treated with
shellac. With a diameter of 11 inches this wood core allowed a blanket covering of plasticine $1 / 2$ inch in thickness, thus giving a total diameter of 12 inches. A board 16 by 24 inches served as the base, and to this was fastened the hemisphere of wood and plasticine. The preparations were complete. Noting the date, May 1st, preparations were complete. Noting the operations commenced. It was eight 1913 , actual operations commenced. It was eig
months later when the finishing touches were applied.

The photograph of a ball such as the moon present some peculiarities. Take a 12 -inch photo of a 12-inch ball. Superimpose the apparent centers, at the same time wrapping the photo paper around the face of the hemisphere. It is immediately apparent that they not correspond and will not fit. The photo paper lacks practically seven inches of covering its prototype. The reason for this is quite evident. If the photo is kept flat and vertical lines projected to the surface of the ball, they coincide perfectly. This tersely explains the method I adopted on account of its simplicity in transposing scale calculations.

A photo of the full moon is very much like the preliminary sketch of the landscape painter. The seas, those great dark regions which even the naked eye disprominent craters are noted. The more important mountain ranges are roughly indicated. But the details of all these are to be shown later. I first selected such a picture, an excellent one from the 5-inch Brashea telescope of D. B. Marsh, Sc.D., F.R.A.S. Being just 12 inches in diameter, it served the purpose admirably of an outline sketch or key. Various points on this were chosen and soon projected onto the model. As the work progressed craters and prominent physical fea-
tures, visible only in other photos, were first given thei tures, visible only in other photos, were first given their
proper locations on this key, that they might thereby proper locations on this key, that
be accurately place on the model.

Jach Paris photo gave in great detail one smal region. Possibly but one or two craters of importance would be shown. Another picture of the same region, but under different lighting conditions, would change the apparent physical features to a remarkable degree. Thus a number of pictures of every district, showing the changes produced by sunlight coming from the eas or from the west, must be carefully compared in orde to arrive at a full understanding of the real topography. With a hundred such photos before me constantly, this task was by far the greatest and of prime importance. There are no twilight shadows on the moon. A glance at a dark spot may lead to the conclusion that a great hole is there, to which the sunlight has not as yet been admitted. Further investigation of it in other pictures reveals the fact that there is no such cavity, and that the shadow is due to the peculiar conformation of an interrening hill. Though the shadows thus appear puzzling and are sometimes very misleading, they are quite necessary for an understanding of the height of a crater wall, and a hundred other measurements of the various conformations of the surface. They simply require due consideration.

The moon is a dead world. The most minute investigation indicates that nothing could be more so. A dried up, wrinkled, wizened, scarred veteran, it bears the marks of terrible conficts, of gigantic struggles. We know not its age. Did water once rush down those wondrous mountain gorges? Did the sea ripple and play about those towering capes Laplace and Heraclide and at times dash madly against those great precipices? We can only guess. Our fancy pictures, in the distant past, smiling vegetation, life, joy, and happiness in a world of glory. It is true there are some indications of this. But death came. Like a mummy it is to-day. Iife departed, embalmed, naught remains but the shrunken, desiccated, cracked carcass. The beauty of life is gone. Its history, its experiences written in the shroud, are in mysterious hieroglyphics, of which man has been able to decipher but little. To-day no grass waves on the hillside. Not a single blade would give the weary traveler a welcome. No bird warbles his cheery song there. Not even the hated snake sun himself upon the many rocks. Not an insect flits abou in quest of prey. Not a breath of air stirs. Not a sig of life appears anywhere. Inconceivable desolation!

Night comes. The sun sinks behind the lofty hills, and suddenly all is dark. No twilight softly intervenes. Cloudless the sky, devoid of air and moisture, no light is refiected or refracted. There can be no diffusion of sunlight under such conditions. Black night sits side by side with brilliant day wherever the rays of the sun are intercepted. Behind the jutting rock, beneath the ledge, within the cavern of broad entrance, it is night, though day reigns supreme with intense brightness al about.

It is quite a surprise to many to learn that the eart presents more light to the moon than it receives in return. Assuming that they possess the same refiective power, the surfaces compare as 27 to 2 . Thus the earth should be credited with reflecting more than thirteen times as much light as its satellite. This light throw upon the moon is known as "earthlight," and is in all respects similar to our moonlight. When the moon be gins its monthly journey around the earth by passing between the sun and us, the earth is "full moon" to it while that body presents the phase of "new moon" to us Thus the greatest amount of "earthlight" reaches the dark portions of the moon at this time. It is this phe nomenon which gives rise to that beautiful sight, "the old moon in the young moon's arms." As the age of the moon increases, this reflected light from the earth gradually lessens until there is none at full moon. Then as light" continues to increase in proportion.

While the moon is making this circuit of the earth $291 / 2$ of our days pass by. Yet she takes all this tim to have but one day and one night. Day brings heat unbearable in its intensity. Scorching as the flames from the inferno, the sun pours his streams of fire hour after hour until the rocks fairly dance with molecular agitation. For fourteen days without a moment's re lief this continues. Then with startling suddennes night appears. A temperature more than 200 degree below zero assails all. Without the kindly protectio of a cloud, stark naxed as it were, and thrust into a temperature of glacial cold from such a bed of warmth the results must be disastrous. Such extremes of heat and cold as these cannot but result in anything less than gigantic destruction. Great yawning chasms appear everywhere on the moon, some of which extend for hundreds of miles. Close scrutiny of these numerous
cracks, a thousand of which have been charted, sug gests to the observer the possibility of some slight extra disturbance resulting in a general disintegration of the whole satellite

Seismic convulsions anpear to have taken place at certain centers in the early history of the moon, producing remarkable results. The exterior of the molten mass had cooled sufficiently to form a crust, a brittle glass-like covering. A large number of the so-called craters had formed. Then with further cooling of the molten interior tremendous expulsive force was exerted bursting the outer shell and throwing out great radiat ing cracks in all directions, like spokes in a whee Lava then oozed up through these openings, in some cases but partly filling them, in others overflowing. Congealing and solidifying under different conditions from the remaining crust, this formation is quite distinctive in appearance, showing as bright streaks. The crater Tycho at the south pole is the center of the greatest system of these light streaks, and thus was a one time in the throes of a seismic disturbance of unparalleled magnitude. Some of the streaks from this center annear to encircle almost half the moon, thereby ifficating the violence attendant upon this great shock In order to give to the eye the effect attained by telescopic observation, I took the liberties of the artist and
departed from scale measurements in one respect. With
180 miles to the inch, a distance of 2 miles on the moon would be 1/90th of an inch on the model. This is less than the thickness of your business card. A lunar
precipice of two miles height would be a very prominent object under proper lighting be a very promiworthy of special attention. Yet an elevation of but $1 / 90$ th of an inch on the model would be merely the thickness of a coat of paint! Therefore the elevations were accentuated in order to produce to the eye a natural appearance, for the strict adherence to scale in this respect would create misconceptions. Careful comparison of photos of the real moon and the sculptured one, under approximately similar lighting, shows
marked contrast. But this was a feature that was not in the least considered important. My aim was not to attain photographic similarity, but to convey to the eye under daylight conditions details apparent only on rare occasions with the telescope. The scientific gave place to the artistic. For such departure I plead merciful consideration from my scientific friends.

In the plaster casts made from the original, many of the finer details have been lost. As a light fall of snow on rough ground spreads a brilliant blanket, while leaving still the form of every stone and every humharshness of the model, softening all to a pleasing degree. A realistic telescopic appearance resulted, which in some respects compensate for the loss of details obtained only after much labor. By a careful application of a coat of paint of a bluish gray tint the maria, white plaster mountains to form in all an ideal full moon.)

A very interesting question appeared while calculating measurements, "What is the smallest possible discernible object on the moon? Could you see a man there? Would a big tree show?" The average human
eye is credited with a power of appreciating an angle of about half a minute of arc. This, however, is quite unintelligible to most people. Let us simplify it. It means that you should see an object one inch in diameter at a distance of about five hundred and fifty-five feet. This would indicate that a "beauty plaster" of one-eighth-inch diameter upon the fair cheek of the débutante should be visible at some sixty-nine feet. Applied to the moon, which averages in size thirty minutes of arc, the unaided eye is capable of discerning a spot measuring one sixtieth of her diameter, or 30 seconds. Now a linear mile on the moon corresponds to 0.87 of a second. Therefore a region one mile square must be magnified by artificial means to equal 30 seconds, that the eye may even perceive it as a point. The power required is evidently about thirty-four. Measurements show that a second of arc represents about two thousand yards on the moon. Thus we would have to magnify an object of that size thirty times to bring it to discernible proportions. Two hundred yards would require ten
times this power, or 300 . Consequently 20 yards would demand a magnifying power of 3,000 ! There must be a very fine atmosphere to admit of the use of a power of 500. One thousand power is quite the limit. Even this latter magnification would bring the moon to a distance of 240 miles, and no object under sixty yards could possibly be detected, if our theory is sound. It is quite evident that a man could not be seen. A big scope, and under conditions of magnification verging upon impracticability, it would be doubtful if an object less than one hundred yards in diameter would be discernible to the human eye as anything but a mere speck. With but one hundred miles separating you from a mountain and with ideal atmospheric conditions, judge what little your naked eye could determine of the details.

\section{Melting Points in Commercial Brasses and} Bronzes

As the result of tests made under the direction of the Inited States Bureau of Mines, the following table of the melting-points of commercial brasses and bronzes has been summarized:

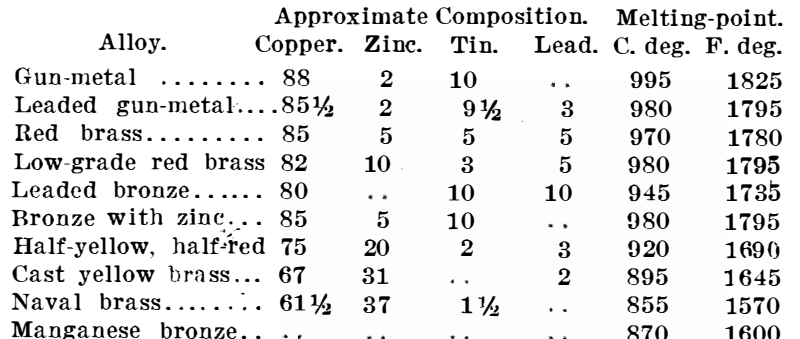

The melting-point given is the "liquidus," or point where the alloy is completely molten. The tests are described in detail in Technical Paper No. 60.-American Machinist. 